\title{
Too Many or Too Few? How Many Lymph Nodes Are Enough?
}

\author{
Teviah E. Sachs, MD, MPH, FACS
}

Section of Surgical Oncology, Department of Surgery, Boston Medical Center, Boston University School of Medicine, Boston, MA

In the current article, Dr. Wang and colleagues use the Surveillance, Epidemiology, and End Results (SEER) database to analyze lymphadenectomy during distal pancreatectomy performed for pancreatic ductal adenocarcinoma. ${ }^{1}$ They sought to identify the minimum number of examined lymph nodes necessary to ensure adequate quality of lymphadenectomy and the impact on overall survival.

The authors found that a minimum of 19 lymph nodes ought to be removed and examined in order to ensure the quality of lymphadenectomy, and that this had a positive impact on overall survival of 7 months or more. The authors appropriately note that their data are limited by the inherent pitfalls of the SEER database, as well as the variations in treatment decisions between institutions.

The utility of lymphadenectomy and its impact on survival in the treatment of cancer has long been a subject of controversy, perhaps most notably for breast cancer. Appropriate lymphadenectomy has run the gamut from Halstead's radical mastectomy ${ }^{2}$ to Wangensteen's further expansion, ${ }^{3}$ and then onward to the slow and methodical limiting of the resection bed led by Fisher and others ${ }^{4,5}$ to the point now where even in selected patients with positive nodal disease, lymphadenectomy is not recommended. ${ }^{6}$ Since then, and with improved systemic therapy, we have seen a somewhat similar progression in the treatment of melanoma, where the utility of axillary, inguinal, and pelvic lymphadenectomy has dropped dramatically over the past decade.

(C) Society of Surgical Oncology 2021

First Received: 7 September 2021

Accepted: 5 October 2021;

Published Online: 22 October 2021

T. E. Sachs, MD, MPH, FACS

e-mail: teviah.sachs@bmc.org
For pancreatic cancer, the answers have not come as quickly. The authors conclude that by obtaining a minimum of 19 lymph nodes, the surgeon can ensure optimal survival. However, there is no consensus in the literature that the actual removal of lymph nodes imparts any improvement in survival for pancreatic cancer. Rather, as the authors later point out, with adequate lymphadenectomy we can improve the accuracy of cancer staging. It is in accurate staging that we benefit the patient, not necessarily in the removal of positive nodes.

In the American Joint Committee on Cancer 8th Edition, pancreatic cancer nodal staging was subdivided into N1 $(\leq 3)$ and $\mathrm{N} 2(\geq 4)$ lymph nodes, and a minimum of 12 lymph nodes was recommended for accurate staging. Yet, based on the data shown by Dr. Wang and colleagues, these patients would be receiving suboptimal lymphadenectomy, and their data are convincing.

If we could be confident in the drainage pattern of pancreatic cancers, then the identification of sentinel lymph nodes, before further lymphadenectomy, would benefit the patient and the surgeon. However, as of yet, the sensitivity and specificity of recent studies is lacking ${ }^{7,8}$ and we must continue to resect lymph nodes en masse with our specimens.

The authors note that the stations of lymph nodes removed cannot be elicited from the database, and certainly this is a limitation of the SEER data. Yet, here again, opinions differ on the role of each nodal station and how their involvement or absence of involvement should be interpreted in the work-up and treatment of a patient. ${ }^{9-11}$ The International Study Group on Pancreatic Surgery advised the removal of stations 10,11 , and 18 for left-sided pancreatectomy. ${ }^{12}$ However, extended lymphadenectomy was not recommended, and others have shown extended lymphadenectomy to increase morbidity without improved survival. ${ }^{13,14}$ This leaves us in a bit of a quandary as pancreatic surgeons. The authors conclude that appropriate 
lymphadenectomy, to include a minimum of 19 lymph nodes, ensures accurate nodal staging and optimal survival, but if the appropriate stations are removed, does the number of lymph nodes, if fewer than 19, leave the patient at a disadvantage? Furthermore, how is one to know, at the index operation, whether or not one has achieved the correct number? If the final number is less than what is desired, is there utility in searching the specimen-or even the patient-for further lymph nodes missed on the initial evaluation? These are not questions that are easily answered. We all strive to achieve adequate lymphadenectomy. Yet, when in the midst of an extremely difficult dissection and the prospect of rooting for further lymph nodes gives us pause, we may be comforted by the words of Barbara Benedek: More isn't always better. Sometimes it's just more.

DISCLOSURES Teviah E. Sachs declares no conflicts of interest.

\section{REFERENCES}

1. Wang W, Shen Z, Zhang J, Chen H, Deng X, et al. A novel criterion for lymph nodes dissection in distal pancreatectomy for ductal adenocarcinoma: a population study of the US SEER database. Ann Surg Oncol. 2021. https://doi.org/10.1245/s10434021-10797-2.

2. Halsted WS. The results of operations for the cure of cancer of the breast performed at the Johns Hopkins Hospital from June, 1889 to January, 1894. Med Class. 1938;3:441-509.

3. Wangensteen $\mathrm{OH}$, Lewis FJ, Arhelger SW. The extended or super-radical mastectomy for carcinoma of the breast. Surg Clin N Am. 1956;36:1051-63.

4. Fisher B, Redmond C, Fisher ER, et al. Ten-year results of a randomized clinical trial comparing radical mastectomy and total mastectomy with or without radiation. $N$ Engl $J$ Med. 1985;312:674-81.

5. Giuliano AE. Sentinel lymphadenectomy in primary breast carcinoma: an alternative to routine axillary dissection. J Surg Oncol. 1996;62:75-7.
6. Giuliano AE, Ballman KV, McCall L, Beitsch PD, Brennan MB, Kelemen PR, et al. Effect of axillary dissection vs no axillary dissection on 10-year overall survival among women with invasive breast cancer and sentinel node metastasis: the ACOSOG Z0011 (Alliance) randomized clinical trial. JAMA. 2017;318(10):918-26.

7. Sadeghi R, Aliakbarian M, Shayegani H, Memar B, Dabbagh VR. The accuracy of sentinel node biopsy by $99 \mathrm{mTc}$-sodium phytate in patients with pancreatic cancer. Ann Hepatobiliary Pancreat Surg. 2020;24(3):277-82.

8. Beisani M, Roca I, Cardenas R, Blanco L, Abu-Suboh M, Dot J, Armengol JR, Olsina JJ, Balsells J, Charco R, Castell J. Initial experience in sentinel lymph node detection in pancreatic cancer. Rev Esp Med Nucl Imagen Mol. 2016;35(5):287-91.

9. Maithel SK, Khalili K, Dixon E, Guindi M, Callery MP, Cattral MS, Taylor BR, Gallinger S, Greig PD, Grant DR, Vollmer CM. Impact of regional lymph node evaluation in staging patients with periampullary tumors. Ann Surg Oncol. 2007;14(1):202-10.

10. Philips P, Dunki-Jacobs E, Agle SC, Scoggins C, McMasters $\mathrm{KM}$, Martin RC. The role of hepatic artery lymph node in pancreatic adenocarcinoma: prognostic factor or a selection criterion for surgery. HPB (Oxford). 2014;16(12):1051-5.

11. LaFemina J, Chou JF, Gönen M, Rocha FG, Correa-Gallego C, Kingham TP, et al. Hepatic arterial nodal metastases in pancreatic cancer: is this the node of importance? J Gastrointest Surg. 2013;17(6):1092-7.

12. Tol JA, Gouma DJ, Bassi C, Dervenis C, Montorsi M, Adham M, et al. Definition of a standard lymphadenectomy in surgery for pancreatic ductal adenocarcinoma: a consensus statement by the International Study Group on Pancreatic Surgery (ISGPS). Surgery. 2014;156(3):591-600.

13. Orci LA, Meyer J, Combescure C, Bühler L, Berney T, Morel P, et al. A meta-analysis of extended versus standard lymphadenectomy in patients undergoing pancreatoduodenectomy for pancreatic adenocarcinoma. HPB (Oxford). 2015;17(7): 565-72.

14. Lee H, Heo JS, Choi SH, Choi DW. Extended versus peripancreatic lymph node dissection for the treatment of left-sided pancreatic cancer. Ann Surg Treat Res. 2017;92(6):411-8. http s://doi.org/10.4174/astr.2017.92.6.411.

Publisher's Note Springer Nature remains neutral with regard to jurisdictional claims in published maps and institutional affiliations. 